\title{
Sexuality Education in Technical and Vocational Institutions in Guyana: Possibilities and Challenges
}

\author{
Hazel E. Simpson
}

\begin{abstract}
This paper reports on the results of an exploratory evaluation of a sexuality education program that was introduced in technical and vocational institutions in Guyana. The rationale for the program is outlined, along with the methodology employed in the evaluation of the program, including the analysis of data from document reviews, telephone and face-to-face interviews, and surveys of facilitators and students' perceptions of the program. The findings of the evaluation are presented and the author offers some considerations to be taken into account when developing and implementing new programs.
\end{abstract}

\section{Background}

There is a growing recognition among educators, health professionals, non-governmental organizations, and national governments worldwide of the need for sexuality education for adolescents and young people. Sexuality education has been described as an "age appropriate, culturally relevant approach to teaching about sex and relationships by providing scientifically accurate, realistic, nonjudgmental information" (UNESCO, 2009, p. 2).

The United Nations Educational, Scientific and Cultural Organization suggests that the ultimate goal of any sexuality education program should be to equip children and young people with the knowledge, skills, and values which they need to make responsible choices about their sexual and social relationships in a world affected by HIV. In addition, that organization identified specific objectives for effective sexuality education, which include:

- $\quad$ to increase knowledge and understanding

- $\quad$ to explain and clarify feelings, values and attitudes

- $\quad$ to develop or strengthen skills; and

- $\quad$ to promote and sustain risk-reduction behavior. (p. 3)

\section{The Sexual and Reproductive Health Profile of Guyanese Young People}

In Guyana, escalating problems in adolescent and youth sexual and reproductive health, including HIV, led to the recognition by several stakeholders that there is a need to strengthen existing sexuality programs as well as implement new ones. A recent survey revealed that Guyana's adolescent fertility rate (births per 1,000 women, 15-19 years) is 88, which is much higher than some neighbouring Caribbean territories. In addition, Guyana's adolescent fertility rate (15-19 years) is much higher than the global average of 44 (World Bank, 2016). Moreover, there is also some indication that sexual activity is 
beginning at a relatively early age. One study found that $4.9 \%$ of women and $12.6 \%$ of men in the 15 24 age group admitted to having their first sexual encounter before they were 15 years old. Also, 15\% of girls between the ages of 15 and 19 years were mothers at the time of the survey (Guyana MICS, 2014). Further, condom use among young people (15-24 years) in Guyana seems to be more widespread among males than females ( $87 \%$ for males; $57 \%$ for females); unprotected sex among young people (15-19 years) in rural areas may be higher than in urban areas, according to McIntosh, Carto, Boodhoo, Roberts, and McIntosh (2013).

Since 2009, there has been an annual reduction in the reported number of HIV cases and number of AIDS-related deaths. Guyana's adult HIV prevalence rate in 2013 was 1.4\%. Between 2008 and 2014, the HIV prevalence rate among the 15-19 age group fluctuated between $2.9 \%$ and $3.5 \%$. In 2014, $1.9 \%$ of young people in the 15-24 age group reported to be living with HIV. In addition, $42 \%$ of the reported cases of sexually transmitted infections were within the 15-24 age group (Guyana AIDS Response Progress Report, 2015).

\section{Sexuality Education in Technical and Vocational Institutions}

Sexuality education in Guyana is delivered principally through the Health and Family Life Education (HFLE) curriculum. Health and Family Life Education, a life skills-based curriculum intervention, is implemented in Grades 1 to 9 in schools in Guyana (CARICOM \& UNICEF, 2010). However, the present Health and Family Life Education curriculum does not cater to the needs of young people for sexuality education in postsecondary and tertiary institutions (e.g., technical and vocational institutions). Technical and vocational education in Guyana is offered by both formal and nonformal educational institutions. Formal educational institutions, like the state-funded Technical Institutes, Guyana Industrial Training Centre, and the Carnegie School of Home Economics, and nonformal institutions, such as the Young Women's Christian Association, Board of Industrial Training, and the Adult Education Association, all offer technical and vocational education.

In 2008, representatives from the Adult Education Association and several other technical and vocational institutions proposed a program to integrate sexuality education into the curricula of their institutions. These institutions cater to a student population whose ages range from 14 years to approximately 25 years. Many of these young people are sexually active, while some are teenage parents (AEA, 2008). In addition, some of these young people have dropped out of secondary school or never had a secondary education (AEA Guyana, 2008). For some young people, technical and vocational institutions offer them a second chance to acquire job knowledge and skills. It is against this background that the technical and vocational institutions recommended that a life skills-based program in sexual and reproductive health and gender-based education should be integrated into the curricula of their institutions. 


\section{Sexual and Reproductive Health and Gender-Based Education}

In order to develop and integrate the course, Sexual and Reproductive Health and Gender Based Education, into the curricula of technical and vocational institutions, the Adult Education Association was named the implementing partner, while technical and financial support was provided by the United Nations Population Fund (UNFPA). The Sexual and Reproductive Health and Gender Based Education curriculum is intended to be delivered over a period of no fewer than 30 hours.

An overarching goal of the program is "an increase in the exercise of reproductive rights and gender equity among adolescents and youths in post-secondary institutions" (Framework for Integrating Sexual and Reproductive Health and Gender Based Education Into Technical and Vocational Institutions, 2008, p. 1). The curriculum is organized around five themes: Understanding Self, Interpersonal Relationships, Gender and Gender-Based Violence, Sexuality, and Reproductive Health.

The implementing partner was also responsible for the provision of teaching and learning resources: curriculum guides, students' workbooks, brochures, flyers, charts, and DVDs. Facilitators participated in workshops of two to four days, focused on the use of the curriculum. Health educators from the Guyana Responsible Parent Association conducted sessions on sexual and reproductive health. These workshops, funded by UNFPA, were held between 2008 and 2013. However, the exploratory evaluation of the program in this paper refers to the 2008-2012 period.

The research questions that guided the exploratory evaluation are:

1. To what extent is the sexual and reproductive health and gender-based education integrated into the curricula of technical and vocational institutions?

2. What are students' and facilitators' perceptions of the sexual and reproductive health and genderbased education?

3. Are there differences in the perceptions of students and facilitators in relation to the sexual and reproductive health and gender-based education?

4. What is the nature of the support given to the implementation of the sexual and reproductive health and gender-based education by administrators of technical and vocational institutions?

\section{Research Related to Curriculum Innovation}

Research on curriculum innovation indicates that change is a developmental process that takes time (Hall, 1979). Research studies also suggest that there are several perspectives related to educational change: rational-scientific/R\&D, political perspective, and the cultural perspective (Sashkin \& Egermeier, 1993). Researchers have also identified some typical stages through which innovations progress: initiation, development, and adoption; implementation, sustainability, and dissemination (Scheirer, 2005). However, there is no linear progression from one stage to the next. Some research suggests that implementation and sustainability are often parallel processes that occur concomitantly and that they are affected by similar program activities (Scheirer, 2005). 
In addition, some research suggests that several factors may have an impact on the implementation and sustainability of a new program. These factors include strong advocacy for the program (Samuels et al., 2013), qualified personnel and teachers' beliefs about their ability, administrative support and adequate resources (Fullan \& Miles, 1992; Patterson, 1997; Sparks, 1988; Weiler, Pigg, \& McDermott, 2003). Furthermore, programs can be sustained depending on the extent to which they can be modified to adapt to the organization (Bergman \& McLaughlin, 1977; Hall, 1979; O'Donnell, 2008; Scheirer, 2005; Shediac-Rizkallah \& Bone, 1998), as well as the extent to which stakeholders believe in the benefits provided by the program (Scheirer, 2005). Barriers to implementation and sustainability include inadequate time and rapid teacher/facilitator turnover (Friend, Flattun, Simpson, Nederhoff, \& NeumarkSztainer, 2014).

\section{Methodology}

\section{Data Collection}

Data were collected in the following ways:

Document review of annual reports and workshop registers of the implementing partner in order to get background information on the program.

Telephone interviews were conducted with program facilitators to determine whether they were still involved with the program.

Questionnaire administered to facilitators and former students for data on course content and organization, fidelity of implementation, training of facilitators, benefits to students, and resources. The questionnaires contained closed-ended questions and one opened-ended question which allowed respondents to state how they benefitted from the program.

Semi-structured face-to-face interviews with administrators of the relevant institutions.

\section{Population and Sample}

The population in this study comprised students and facilitators from technical and vocational institutions, both rural and urban, that had agreed to integrate the sexuality education program into their curricula.

Thirty (30) students who had completed the sexuality education program offered by one participating institution, the Board of Industrial Training at one of its training sites on the West Coast of Berbice, prior to 2012, were asked to complete the students' questionnaire. These were the students who were accessible at the time of data collection. Seventy-seven percent of these students are between the ages of 15 to 22 . A majority (24) of the students are female and 27 of these students completed secondary school. 
Fifty-eight persons who responded to telephone calls comprised the facilitators' sample for the telephone interview. A convenience sample of 16 facilitators, who were attending a workshop, responded to the facilitator's questionnaire. A majority (10) of the facilitators who responded to the questionnaire are female. In addition, a representative from the Ministry of Education and administrators of five participating institutions made up the sample.

\section{Data Analysis}

To determine the extent to which the sexuality education program was integrated into the curricula of institutions, the researcher analyzed data from document reviews, telephone interviews, surveys, and semi-structured interviews. Quantitative analyses included tallying, calculating mean, t-tests, and chi square. Means were calculated for the factors of facilitators' and students' perceptions. T-tests and chi square tests were conducted to explore differences in perceptions of facilitators and students. The researcher conducted content analysis for semi-structured interview transcripts and open-ended responses on the facilitators' and students' questionnaires.

\section{Results: The Extent to Which the Sexuality Education Program Is Integrated Into Technical and Vocational Institutions}

Participating institutions. The annual reports and other records of the implementing partner in the program provided a general picture of the number of institutions that had indicated an interest in participating in sexual and reproductive health and gender-based education, their location, and the number and gender of facilitators trained (Table 1 and Figure 1). Between 2008 and 2010, 79 people from 15 organizations/institutions participated in training to facilitate the sexuality education program. Six of these institutions are formal state-owned educational institutions. The number of institutions increased by four in 2010, which included one faith-based organization. The majority of these institutions carry out their activities primarily in urban areas.

Most of the facilitators trained between 2008 and 2010 are from two institutions, Adult Education Association (24\%) and Board of Industrial Training (24\%) (Figure 1). Both are nonformal institutions and have the potential to reach a wide cross section of young people outside of the formal education system. In addition, there is a preponderance of female facilitators (71\%). 


\section{Table 1}

Participating institutions

\begin{tabular}{|c|c|c|c|c|c|}
\hline \multirow[t]{2}{*}{ Institution } & \multicolumn{2}{|c|}{ Area of Activity } & \multirow{2}{*}{$\begin{array}{l}\text { No. of Facilitators } \\
\text { Trained 2008-2009 }\end{array}$} & \multirow{2}{*}{$\begin{array}{l}\text { No. of Facilitators } \\
\text { Trained } 2010\end{array}$} & \multirow{2}{*}{$\begin{array}{c}\text { Total } \\
\text { 2008-2010 }\end{array}$} \\
\hline & Urban & Rural & & & \\
\hline $\begin{array}{l}\text { Adult Education Association } \\
\text { (AEA) }\end{array}$ & $\bullet$ & $\bullet$ & 12 & 7 & 19 \\
\hline $\begin{array}{l}\text { Board of Industrial Training } \\
\text { (BIT) }\end{array}$ & $\bullet$ & - & 15 & 4 & 19 \\
\hline $\begin{array}{l}\text { Young Women's Christian } \\
\text { Association (YWCA) }\end{array}$ & $\bullet$ & & 3 & 2 & 5 \\
\hline Critchlow Labour College & $\bullet$ & & 4 & - & 4 \\
\hline $\begin{array}{l}\text { Guyana Industrial Training } \\
\text { Centre (GITC) }\end{array}$ & $\bullet$ & & 2 & - & 2 \\
\hline $\begin{array}{l}\text { Carnegie School of Home } \\
\text { Economics (CSHE) }\end{array}$ & - & & 2 & 2 & 4 \\
\hline $\begin{array}{l}\text { Technical and Vocational } \\
\text { Education Council (TVET) }\end{array}$ & & & 2 & - & 2 \\
\hline $\begin{array}{l}\text { Ministry of Youth and Culture } \\
\text { Skills Training Centre }\end{array}$ & & - & 4 & - & 4 \\
\hline $\begin{array}{l}\text { Institute of Distance and } \\
\text { Continuing Education }\end{array}$ & $\bullet$ & & 7 & - & 7 \\
\hline Guyana Youth Business Trust & $\bullet$ & & 1 & 1 & 2 \\
\hline $\begin{array}{l}\text { Government Technical Institute } \\
\text { (GTI) }\end{array}$ & $\bullet$ & & 3 & - & 3 \\
\hline $\begin{array}{l}\text { New Amsterdam Technical } \\
\text { Institute (NATI) }\end{array}$ & $\bullet$ & & - & 2 & 2 \\
\hline $\begin{array}{l}\text { Essequibo Technical Institute } \\
\text { (ETI) }\end{array}$ & & $\bullet$ & - & 2 & 2 \\
\hline Linden Technical Institute (LTI) & $\bullet$ & & - & 2 & 2 \\
\hline Roadside Baptist Skills Training & & $\bullet$ & - & 2 & 2 \\
\hline Total 15 & & & & & 79 \\
\hline
\end{tabular}




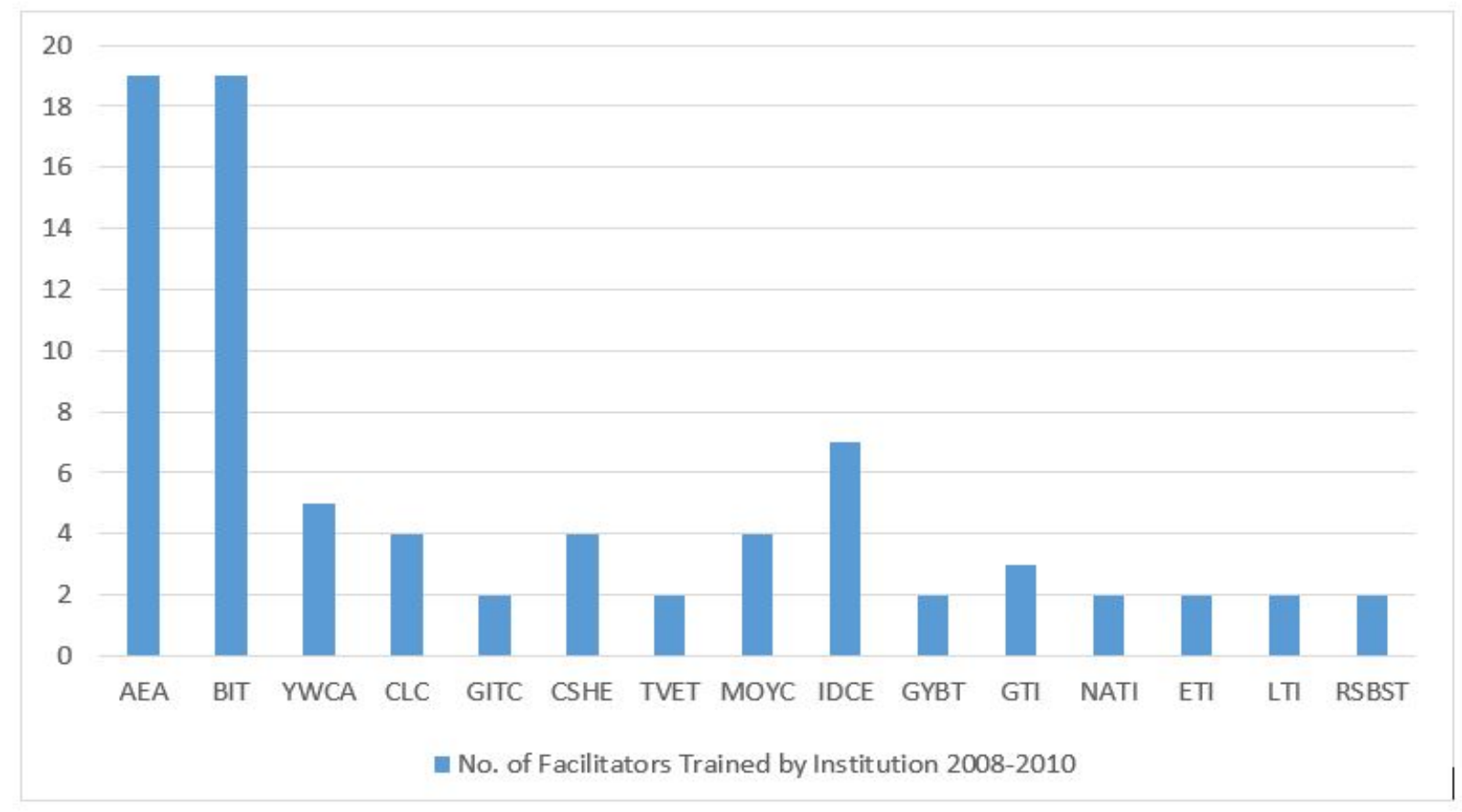

Fig. 1: Facilitators trained

Facilitators who are actually teaching the course. Telephone interviews conducted with 58 of the facilitators who had been trained revealed that only 15 (26\%) of them were actually teaching the course at the time of the interview. The main reasons given by facilitators for not teaching the course are that it is not offered by the participating institution (48\%) or they are no longer employed by a participating institution (32\%). A few of the facilitators had migrated to other countries, while others claimed that they had not been asked to teach the course. However, several facilitators indicated that even though their institution did not formally offer the course, they use the knowledge and skills acquired from the training to counsel students or conduct informal sessions with their class or other groups and individuals in their community.

\section{Results of the Facilitators' Questionnaire Survey}

Institutions offering the sexuality education program and the mode of its delivery. First, the survey sought to find out whether sexuality education is offered at the institutions with which the facilitators are affiliated, and if the course is offered, how it is scheduled. Facilitators were also asked to identify the mode of delivery of the course and the time allocated for teaching the course. The results of the facilitators' survey reveal that a minority, four (4) out of the eleven (11) institutions to which they belong, offer sexuality education. The institutions identified as not offering the course are the same as those identified by the respondents of the telephone interview. 
Of the facilitators who indicated that their institutions offer the course, a majority (75\%) said that the course was offered as a separate subject/distinct module. These facilitators belong to two institutions, the Board of Industrial Training and the Adult Education Association. Other facilitators (25\%) indicated that some of the course content is integrated into other subjects. On average, two to three hours per week is allocated for teaching the course and it is delivered via the face-to-face modality.

Facilitators' perceptions of sexuality education. The facilitators' questionnaire included questions related to critical aspects of the course, Sexual and Reproductive Health and Gender Based Education.

The categories of interest are (Figure 2):

- Content of the course

- Fidelity/implementation of the course

- Organization of the course

- Training of facilitators

- Benefits of the course to students

- Impact of the course on students

- Materials/resources

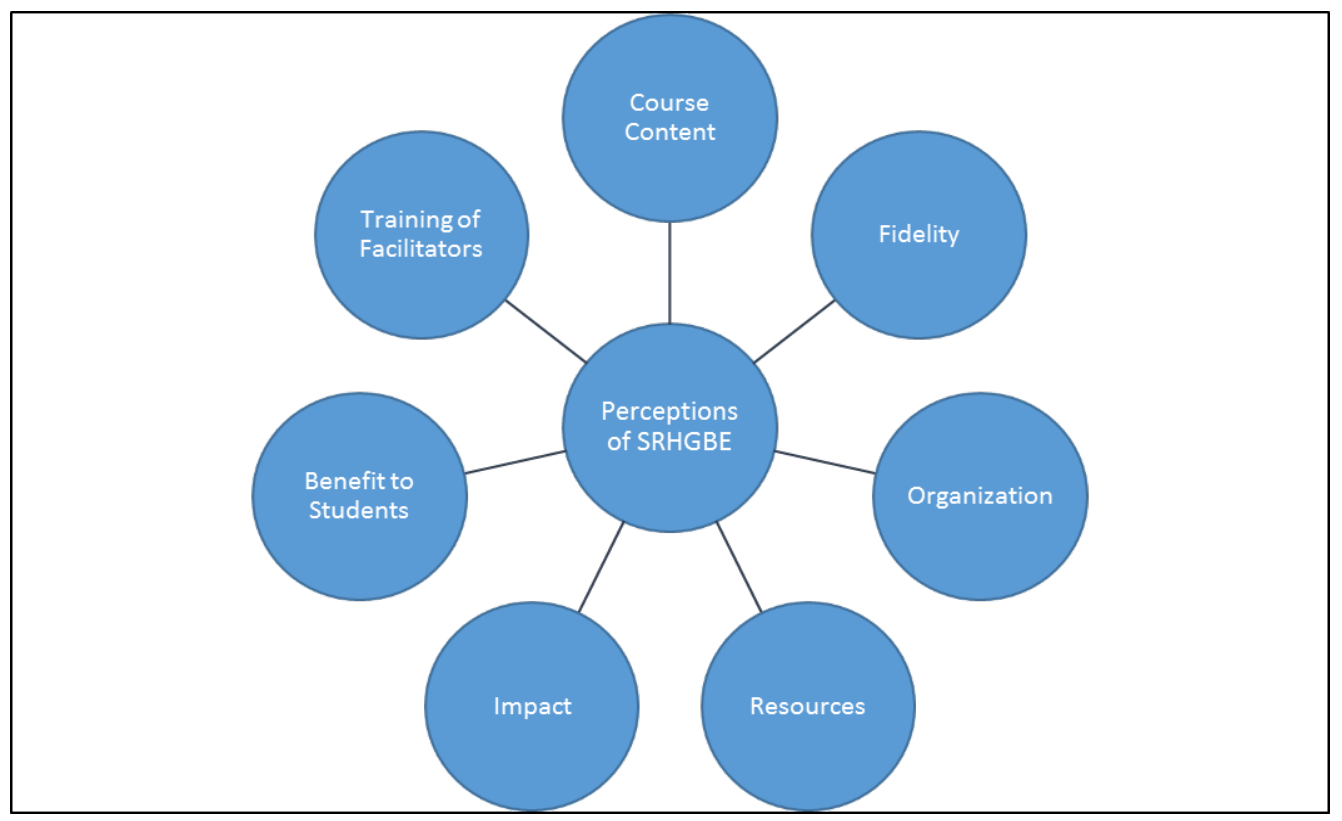

Fig. 2: Facilitators' perceptions

The mean scores of responses in the various categories outlined in the facilitators' questionnaire are shown in Table 2 below. 


\section{Table 2}

Mean score on variables*

\begin{tabular}{|l|c|c|}
\hline \multicolumn{1}{|c|}{ Variable/Category } & No. of Items & Mean Score \\
\hline Content of course & 5 & 3.5 \\
\hline Fidelity & 2 & 3.1 \\
\hline Organization of the course & 3 & 3.3 \\
\hline Training of facilitators & 3 & 3 \\
\hline Benefit of course to students & 5 & 3.3 \\
\hline Impact of course on students & 3 & 3.3 \\
\hline Materials/resources & 3 & 3.2 \\
\hline *Rating scale used was 1 to 4, with 1 being the least favourable and 4 being the most favourable.
\end{tabular}

Course content examines the degree to which facilitators were satisfied with the content of the course, including its appropriateness and relevance for students' needs. As the mean (on a scale of 1 to 4) indicates, the facilitators generally gave very positive responses (mean $=3.5$ ). The most positive responses relate to the up-to-date nature of the course content (mean $=3.6$ ) and the appropriateness of the course content for adolescents (mean $=3.6$ ). The lowest mean of the category relates to the appropriateness of the course content for students of diverse cultural and ethnic backgrounds (mean = 3.3). On the whole, respondents are very satisfied with the course content.

Fidelity examines the degree to which facilitators implemented the course in the way it was intended. There were two items in this category which sought to find out whether the course was implemented the way it was laid out in the course module and whether facilitators found it difficult to implement the course. The mean suggests that most facilitators have given relatively positive responses (mean $=3.1$ ). The lowest mean of the category relates to whether facilitators implemented the course the way it was laid out in the module (mean $=2.9$ ). This mean suggests that several facilitators $(38 \%)$ reported they did not implement the course in the way it was intended.

Organization of the course examines the degree to which facilitators were satisfied with the objectives of the course and the organization of the course content, including flexibility to adapt content to meet students' needs. The mean score suggests that facilitators have generally given positive responses (mean =3.3). The most positive mean relates to satisfaction that the course is organized in such a way that it is easy to understand and deliver (mean $=3.5$ ), while the lowest mean score corresponds with the ability to adapt the curriculum to meet students' needs (mean $=3.2$ ). 
Training refers to facilitators' perceptions of the adequacy of the training they received to facilitate the course, in terms of the knowledge/content acquired and the duration of the training. As the mean score indicates, facilitators have generally given a moderately positive response (mean $=3$ ). They were satisfied that the training equipped them with adequate skills/teaching strategies to facilitate the course and this item received the highest mean score of the category (mean $=3.4)$. However, a significant number $(50 \%)$ felt that the time set aside for training was inadequate and this item received the lowest mean score of the category $($ mean $=2.6)$.

Benefits refer to facilitators' perceptions of how students benefitted from the course in terms of knowledge and skills acquired and attitude formation. The mean score shows that facilitators have given positive responses (mean $=3.3$ ). The most positive mean is related to satisfaction that the course gave students opportunities to interact and share ideas and opinions (mean $=3.5$ ). The lowest mean of the category seems to indicate that facilitators have a moderately favourable perception that the knowledge and skills students acquired led to changes in their behaviour (mean $=3.1$ ). Generally, facilitators feel that students have benefitted from the course. Another area of interest was finding out facilitators' perceptions of the impact of the course on students. As the mean score indicates, facilitators have given positive responses $($ mean $=3.3)$. The most positive mean corresponds to satisfaction that the course promoted open discussion among students (mean $=3.5$ ), while the lowest mean score relates to the impact of the course on students' attitudes (mean $=3.2$ ).

The final area of interest was, materials, provided for the course in terms of its relevance, user friendliness, and cost. Again, the mean score is good (mean = 3.2). There was one negative item in the category, which stated that the materials were expensive to reproduce. As the mean indicates, the facilitators disagreed with this position (mean $=2.8$ ). The highest mean of the category relates to satisfaction that the materials were relevant to the course content (mean $=3.5$ ).

Facilitators were also asked to indicate the extent to which a range of resources/materials are available for teaching the course. The rating scale used was 1 to 4 , with 1 being the least available and 4 the most available. The means show that, the resources/materials that are least available for use are audiovisual formats such as DVDs (mean =1.4) and CDs (mean = 1.5), computer with Internet access (mean = 2.1), and up-to-date text books and reference materials (mean $=2.4$ ). The module, Framework for Integrating Sexual \& Reproductive Health \& Gender Based Education, seems to be the most readily available resource for facilitators (mean $=3.2$ ).

\section{Results of Facilitators' Open-ended Question: Benefits of Sexuality Education}

The qualitative analyses indicated that a majority of the facilitators felt that the program equipped them with the knowledge and skills needed to teach the course. They seem to have gained a lot of self-efficacy regarding their ability to deliver the curriculum. The statements below reflect this view: 
This course has widened my knowledge ... and I'm equipped to deal with my students.

This course ... was very informative in terms of what is happening in the society and among our young people. This will cause [help] us to understand how to deal [work] with youths.

I have learnt how to relate to students on a one-on-one basis. I have been given an abundance of information to use in [training] sessions.

Some facilitators explained that the course brought about a change in their attitude to issues relating to sexuality. Other facilitators explained that they are more tolerant of people who are different from them. It seems as if some facilitators have begun to examine their beliefs and change the way in which they interact with their students:

As a person, it [the course] has change[d] my thinking of certain aspects, especially lesbians and gays. I will be more tolerant and seek to understand the person before making decisions.

I have learnt ... and to be more tolerant when dealing with others.

I became a changed individual. I became more accommodating.

\section{Results of the Students' Questionnaire Survey: Students' Perceptions of Sexuality Education}

The student's questionnaire included questions concerning critical aspects of the course, Sexual and Reproductive Health and Gender Based Education. The categories of interest are (Figure 3):

- Content of the course

- Materials

- Benefits of the course to students/participants

- Impact of the course on students/participants

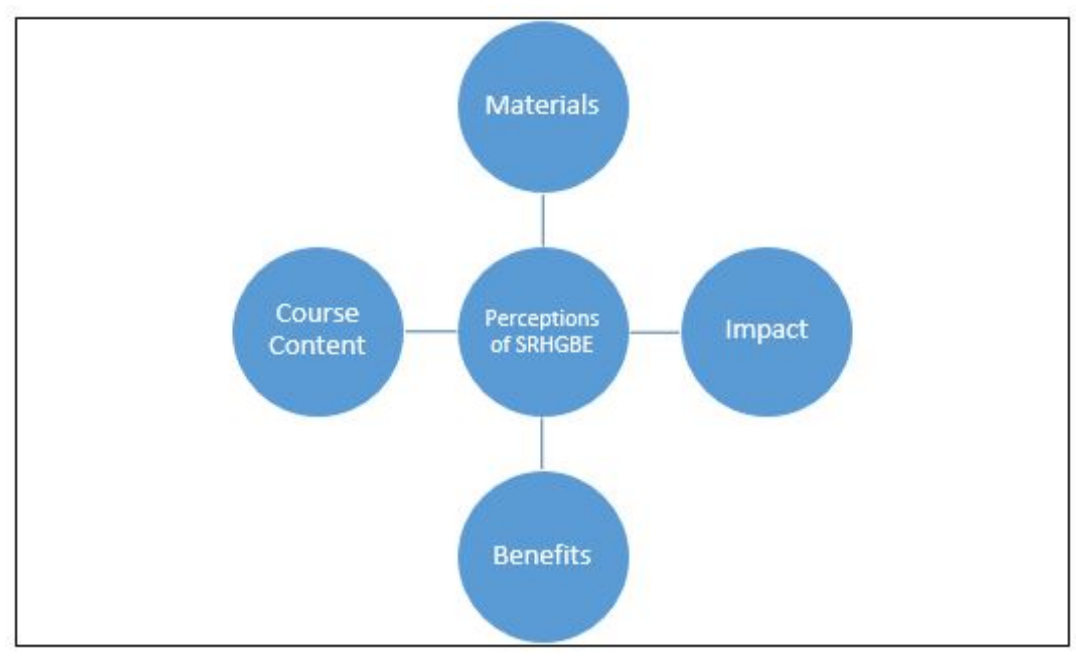

Fig. 3 Students' perceptions 
The mean scores of responses in the various categories outlined in the students' questionnaire are presented in Table 3.

\section{Table 3}

Mean score on variables*

\begin{tabular}{|l|c|c|}
\hline \multicolumn{1}{|c|}{ Variable/Category } & Number of Items & Mean \\
\hline Content of course & 4 & 3.5 \\
\hline Materials & 2 & 3.1 \\
\hline Benefits & 5 & 3.2 \\
\hline Impact & 3 & 3.8 \\
\hline
\end{tabular}

*Rating scale used was 1 to 4 , with 1 being the least favourable and 4 the most favourable.

Course content examines the degree to which students were satisfied with the course content. The mean score (on a scale of 1 to 4 ) shows that students generally have given very positive responses (mean $=$ 3.5). The most positive response relates to satisfaction that the issues addressed by the course were relevant to the needs of all students (mean $=3.7$ ). The lowest mean of the category relates to suitability of the content for adolescents (mean $=2.9)$. A minority of the respondent $(20 \%)$ did not feel that the content was always suitable for adolescents. Overall, respondents are satisfied with the course content.

Another area of interest was respondents' perceptions of the materials used to conduct the course. The mean score suggests that respondents gave relatively positive responses (mean $=3.2$ ). The highest mean of the category relates to satisfaction with the relevance of the materials to the course content (mean = 3.6). Respondents were obviously very satisfied that the materials were relevant to the course content. However, respondents were not entirely satisfied that the materials were always user-friendly (mean = 2.8).

Benefits refer to students' perceptions of how they benefitted from the course in terms of knowledge and skills gained and attitude formation. As the mean score shows, responses were overall relatively positive (mean $=3.2$ ). Students were very satisfied that the knowledge and skills they acquired contributed to a change in attitudes (mean $=3.7$ ). The lowest mean of the category relates to the idea that the course gave students adequate knowledge and skills to make decisions about their reproductive rights (mean $=2.7$ ). This mean suggests that students are not entirely satisfied or convinced that they acquired enough knowledge and skills to make decisions about their reproductive rights.

The survey also sought to find out students' perceptions of the impact that the course had on them. The mean score shows that students gave very positive responses (mean $=3.8$ ). The highest means were in relation to satisfaction that the course had a positive impact on their attitude (mean $=3.8$ ) and that the course promoted open discussion among students (mean $=3.8$ ). There was also satisfaction among 
students that they now know much more about their sexual and reproductive rights and gender violence than when the course began (mean $=3.7$ ).

Students were also asked to indicate the extent to which a range of resources were available for use during the course. The scale used was 1 to 4 , with 1 being the least available and 4 being the most available. The means indicate that the materials/resources that the students felt were least used were multimedia projector (mean $=1.4)$, CDs (mean $=1.5)$, DVDs (mean $=1.5)$, videos (mean $=1.5)$, computer with Internet access (mean $=2.1$ ), and charts and pictures (mean $=2.2$ ). The students felt that the resources that were available were up-to-date books and reference materials (mean $=3.3$ ) and the module Framework for Integrating SRH\&GBE (mean = 3.1). Their perception was similar to that of the facilitators.

\section{Are There Significant Differences in the Perceptions of Facilitators and Students in Relation to Sexuality Education?}

The data permitted an analysis of the relationship between facilitators' and students' perceptions of the following aspects/variables of the course:

- Course content

- Materials

- Benefits of the course to students

- Impact of course on students

The chi square test was used to determine whether there were significant differences in the perceptions of facilitators and students as it relates to the four aspects of the course shown above. The chi square test revealed that there are no significant differences in the perceptions of facilitators and students as it relates to course content, resources used, benefits, and impact of the course on students ( $x 2=0.0346, p=.05$ ). That is, overall facilitators and students perceived those aspects of the course the same way. Further analysis was done to determine if there were significant differences in the perceptions of facilitators and students with regard to the following item: The course had a positive effect on students' attitude. The TTest revealed that there was a significant difference in the perceptions of facilitators and students as it relates to the item above $(t=2.31, p=.05)$. Namely, students felt much more strongly than their facilitators that the course had a positive effect on them.

\section{Results of Students' Open-Ended Question: Benefits of Sexuality Education}

The qualitative analyses of students' responses bolstered the earlier finding that students felt strongly that they had acquired more knowledge, particularly about their sexual and reproductive health, as a result of the course. Others indicated that they developed skills, including decision making and communication:

I know more about my body. And can share with others.

I learnt more about my sexual [and] reproductive health and how to practice safe sex. 
I am able to make wise choices.

I have learnt to be more open when speaking on matters pertaining to SRH [sexual and reproductive health] issues.

One student even felt that the course had brought about a change of attitude: I changed my attitude towards sexuality.

\section{Administrative Support for Sexuality Education}

The interviews with administrators of technical and vocational institutions and the Deputy Chief Education Officer (Technical) of the Ministry of Education revealed that a majority (4 out of 6) of these administrators were aware of the new sexuality education program. Interestingly, one administrator who was unaware of the program, had two trained facilitators affiliated with that institution.

The Ministry of Education's role in implementing the program was limited to helping the Adult Education Association organize training for facilitators. Moreover, it was found that the Ministry of Education has no documented policy on sexuality education at the postsecondary level. The one commonality across the five administrators and the Education Officer interviewed, was that they all agreed that sexuality education should be integrated into the curricula of technical and vocational institutions.

\section{Discussion}

This study adds to our understanding of the challenges and opportunities related to implementing and sustaining curriculum reform. One key finding is that after much investment in time and financial resources in the training of facilitators and the development of the curriculum, sexuality education was not integrated into the curricula of most of the participating technical and vocational institutions. In this study, a majority of the facilitators are not teaching the course and even fewer institutions are offering sexuality education, either as a stand-alone course or integrated into other courses. This result is not completely surprising, as prior research has found that many of the curriculum reforms attempted in education have not been sustained. Numerous explanations have been offered for this state of affairs.

From the facilitators' perspective, the foremost reason for them not teaching the course was that the institution did not offer it. But, facilitator turnover was another reason for the unsustainability of the course. In fact, a significant number of the facilitators are no longer employed by a participating institution. Migration to another country also had a minor impact on the reduction in the number of persons available to facilitate the course. In their study, Friend and colleagues (2014) identified teacher turnover as an important barrier to effective implementation and sustainability of new programs. This finding suggests that developers of curriculum reform should plan for ongoing training and support of teachers/facilitators if the innovation is to be sustained (Berman \& McLaughlin, 1977). In addition, decisions about the sustainability of innovations, including ongoing training, should be made early in the development stage of a project so that administrators at the district (Ministry of Education) and school levels can be prepared for their roles when the project is implemented. 
However, some facilitators were able to adapt the new curriculum to suit the environment in which they work. Even though their institution was not offering the course in sexuality education, they reported that they used the course content and skills gained from the training in other ways: to counsel students, have informal discussions with their class and other groups and individuals in their community, and integrate the content into other courses. Like this finding, prior studies have found that: new programs are implemented and sustained depending on the extent to which they can be modified by stakeholders to adapt to their organization; there can be sustainability for at least some aspects of the program; and sustainability may occur at levels other than the organizational level, including the individual level (Hall, 1979; Scheirer, 2005; Shediac-Rizkallah \& Bone, 1998). Further, Berman and McLaughlin (1977) argue also that the implementation of a new project could be seen as effective if "mutual adaptation" occurs, in which the project is adapted to its institutional context. Thus, a practical implication of this study is that evaluators of curriculum reform should not conclude that a project has failed just because the innovation is not sustained in its original form.

The findings of this study suggest that the developers of the sexuality education program underestimated the role of administrators in the successful implementation and sustainability of new programs. In the case of the formal institutions, even though the Deputy Chief Education Officer (Technical) was aware of the new program, little effort was made to ensure that a policy decision on sexuality education in postsecondary institutions was taken by the Ministry of Education. Without this policy directive from the Ministry of Education, very few administrators at the institution/school level would be inclined to "disrupt" their programs in order to integrate a new course. The absence of a policy directive from the Ministry of Education suggests that there might be a lack commitment on their part for the long-term stability of the new program. Bergman and McLaughlin (1977) contend that early and continued support from district managers is an important factor in the implementation and sustainability of new projects. Moreover, McLaughlin (1990) explains that stakeholder commitment to a new initiative can occur after mandated involvement once there is administrative support.

Administrative support for new projects is important for another reason. As prior studies have shown, administrators can create the organizational climate of acceptance for the innovation in their institutions (Bergman \& McLaughlin, 1977). Administrators who are supportive of new initiatives are often willing to make scheduling and staffing decisions that include the class or course involved (Friend et al., 2014; Scheirer, 2005). The administrator therefore plays a crucial role as the "gatekeeper of change" (Bergman \& McLaughlin, 1977). As several facilitators in this study have pointed out, no provision was made by the administrators of their institution for scheduling the course and they were never asked to teach it. The lesson to be learnt here is that administrative support for a new initiative is vital to its chances of success.

Samuels et al. (2013) suggest that advocacy, which includes activities and interventions aimed at raising awareness and building support and ownership, is critical for the successful implementation and continuation of sexuality education programs. The results of the study being reported here reveal that some administrators of technical and vocational institutions were unaware of the new sexuality education program. It is therefore inconceivable that these stakeholders would support and take ownership of a program they know little or nothing about. However, stakeholders' awareness and support for new 
projects seldom occur by chance. Advocacy has to be planned for and should be ongoing as stakeholders need to be continually brought on board to own the project (Samuels et al., 2013).

Further, this study found that both facilitators and students have a positive perception of the course, particularly as it relates to the knowledge and skills they acquired and the impact it had on attitude formation and instructional practices. This finding suggests that facilitators are receptive to the idea of sexuality education and this is good for future efforts to integrate sexuality education into the curricula of technical and vocational institutions. Research has found that high levels of self-efficacy among teachers usually means that they are willing to take risks and participate in the change process (Sparks, 1988). In addition, researchers suggest that change is likely to occur when people inside the school examine their beliefs and change their instructional practices to suit their revised beliefs (Patterson, 1997; Sashkin \& Egermeier, 1993). This finding suggests also that the program did achieve some of the objectives identified by UNESCO (2009) for effective sexuality education: to increase knowledge, develop skills, and clarify attitudes among young people.

\section{Limitation and Conclusions}

This paper provided useful insights into the challenges and possibilities of integrating sexuality education into the curricula of technical and vocational institutions in Guyana. It highlights the importance of administrative support in the implementation and continuation of curriculum innovation. It also reminds evaluators that a deeper examination of innovations that appear to have failed, may reveal that teachers and students often adapt innovations to their peculiar needs and circumstances. However, some of its findings may not be relevant in other contexts, since the sample of facilitators and students was limited and may not be representative of the broader population. Nonetheless, the findings provide some evidence that the challenges of integrating sexuality education into the curricula of technical and vocational institutions are not insurmountable.

\section{References}

Adult Education Association of Guyana. (2008). Initiative outline. Georgetown, Guyana.

Berman, P., \& McLaughlin, M. (1977). Federals programs supporting educational change, factors affecting implementation and continuation. Santa Monica, CA: Rand Corporation.

Bureau of Statistics, Ministry of Health \& UNICEF. (2015). Guyana multiple indicator cluster survey 2014, key findings. Georgetown, Guyana.

Caribbean Community and Common Market \& UNICEF. (2010). A strategy for strengthening health and family life in CARICOM member states. Georgetown, Guyana. 
Framework for integrating sexual and reproductive health and gender based education into technical and vocational institutions. (2008). Georgetown, Guyana: UNFPA.

Friend, S., Flattun, C., Simpson, D., Nederhoff, D., \& Neumark-Sztainer, D. (2014). The researchers have left the building: What contributes to sustaining school-based interventions following the conclusion of formal research support? Journal of School Health, 84(5), 326-333.

Fullan, M., \& Miles, M. (1992). Getting reform right: What works and what doesn't. Phi Delta Kappan, 73(10), 744-752.

Hall, G.E. (1979). The concerns-based approach to facilitating change. Educational Horizons, 57(4), 202-208.

McIntosh, E., Carto, M., Boodhoo, S., Roberts, G., \& Mclntosh, T. (2013). A qualitative research study on HIV vulnerability among young key affected populations in Guyana. Georgetown, Guyana: UNICEF.

McLaughlin, M. (1990). The Rand change agent study revisited: Macro perspectives and micro realities. Educational Researcher, 19(9), 11-16.

Ministry of Health. (2015). Guyana aids response progress report. Georgetown: Guyana.

O'Donnell, C. (2008). Defining, conceptualizing, and measuring fidelity of implementation. Review of Educational Research, 78(1), 33-84.

Patterson, J. (1997). Coming clean about organizational change. Arlington, VA: American Association of School Administrators.

Samuels, F., Kivela, J., Chetty, D., Herat, J., Castle, C., Ketting, E., et al. (2013).

Advocating for school-based sexuality education. Sex Education, 13(2), 204-213.

Sashkin, M., \& Egermeier, J. (1993). School change models and processes: A review and synthesis of research and practice. Washington, DC: Office of Educational Research and Improvement.

Scheirer, M. (2005). Is sustainability possible? American Journal of Evaluation, 26(3), 320-347.

Shediac-Rizkallah, M., \& Bone, L. (1998). Planning for sustainability of community-based health programs: Conceptual frameworks and future directions for research. Health Education Research, 13(1), 87-108.

Sparks, G. (1988). Teachers' attitude toward change and subsequent improvements in classroom teaching. Journal of Educational Psychology, 80(1), 111-117.

UNESCO. (2009). International guidelines on sexuality education. Paris, France.

Weiler, R., Pigg, R., \& McDermott, R. (2003). Evaluation of the Florida coordinated school health program, Journal of School Health, 73(1), 3-8.

World Bank. (2016). Adolescent fertility rate. Retrieved from data.worldbank.org/indicator 


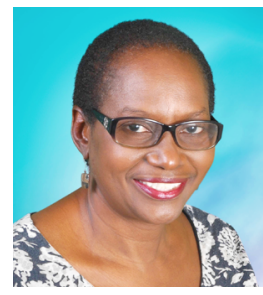

Hazel E. Simpson is a former high school teacher of History and Social Studies. Now a Teacher Educator in the Faculty of Education and Humanities, University of Guyana, she teaches courses in Social Studies Education and Curriculum Development and Evaluation. She is also an examiner for national Social Studies Examinations for the Ministry of Education, Guyana, and the holder of BA, Dip.Ed., and Med. Degrees from the University of Guyana. 